Research Article

\title{
Experimental Research on the Mechanical Behavior of Lime-Treated Soil under Different Loading Rates
}

\author{
Yue Qiang' and Yulong Chen ${ }^{2}$ \\ ${ }^{1}$ College of Civil Engineering, Chongqing Three Gorges University, Chongqing 404000, China \\ ${ }^{2}$ Department of Civil Engineering, The University of Tokyo, Tokyo 113-8656, Japan \\ Correspondence should be addressed to Yulong Chen; 673054399@qq.com
}

Received 29 April 2015; Revised 7 June 2015; Accepted 8 June 2015

Academic Editor: Ana S. Guimarães

Copyright (c) 2015 Y. Qiang and Y. Chen. This is an open access article distributed under the Creative Commons Attribution License, which permits unrestricted use, distribution, and reproduction in any medium, provided the original work is properly cited.

\begin{abstract}
In order to study the mechanical behavior of lime-treated soil under different loading rates, a series of monotonous three-axial compression tests are carried out under different lime contents, different loading rates, and different curing periods. The test results indicate that the lime content can significantly improve the mechanical behaviors of soil, such as shear strength and elastic modulus. On the other hand, three-axial compression test of soil is carried out under the loading rate ranging from $0.1 \% / \mathrm{min}$ to $8 \% / \mathrm{min}$. Experimental results indicate that the mechanical behavior of lime-treated soil is sensitive to loading rate. Besides, the corresponding relationship between internal friction angle, cohesion, lime content, and loading rate is discussed. The results indicate that the loading rate almost has no influence on internal friction angle but significant influence on lime content. Cohesion is affected by lime content and loading rate. Shear strength, elastic modulus, and cohesion all increase with the increase of loading rate. Longer curing period is associated with greater parameter value. Shear strength, elastic modulus, and internal friction angle all firstly increase and then decrease when lime content increases, which all reach the maximum at $6 \%$.
\end{abstract}

\section{Introduction}

During the construction of highways, railways, and airports, although there are rich soil resources in the railway line, they cannot be used as filling materials for subgrade due to poor mechanical properties. Lacking of high-quality filling materials along the railway line to be constructed and transporting large quantities of high-quality filling materials from outside result in a substantial increase in project costs, which makes the treated soil come into being. Lime can stabilize subgrade, pavement, and the soil with low bearing capacity [1]. It is of practical significance to study its physical and mechanical properties, for the soil treated with lime is the most commonly used subgrade filler.

So far, lots of research results on whether mixing lime into soil can improve its mechanical properties have been achieved. Bian et al. [2] have carried out relevant experiment to study the strength and expansion properties of lime-treated expansive soil. Phanikumar et al. [3, 4] have studied the physical and mechanical properties of the soil, respectively, treated with lime, fly ash, and cement. Amu et al. [5] have carried out relevant research on the strength of the soil which has been mixed with lime. Yarbaşi et al. [6] have studied the parameters such as compressive strength, California bearing ratio, ultrasonic wave, and resonance test and other parameters of the soil, respectively, treated with lime, fly ash, and cement after freeze-thaw cycles. Zhang and Cao [7] have studied the properties of the expansive soil, respectively, treated with lime and fly ash. Bekki et al. [8] have studied the bearing capacity and durability of lime-treated soil and cement-treated soil.

The mechanical property of geoengineering materials under different loading rates has always been an important research topic. Zhang et al. [9] studied the mechanical behavior and particle breakage characteristics of subgrade material under different strain rates. Díaz-Rodríguez et al. [10] studied the impact of loading rate on undrained threeaxial shear strength. Martindale et al. [11] proposed a plastic constitutive model that is related to the strain rate of clay and verified the sensitivity of model parameters. Sorensen 
TABLE 1: Index properties of the soil materials.

\begin{tabular}{lcc}
\hline Serial number & Physical property index & Values \\
\hline 1 & Specific gravity & 2.68 \\
2 & Liquid limit $/ \%$ & $56 \%$ \\
3 & Plastic limit $/ \%$ & $35 \%$ \\
4 & Plasticity index $/ \%$ & $23 \%$ \\
5 & Maximum dry density $/\left(\mathrm{g} / \mathrm{cm}^{3}\right)$ & 1.69 \\
6 & Optimum moisture content $/ \%$ & 20.60 \\
7 & Silt content $/ \%$ & 62 \\
8 & Clay content $/ \%$ & 38 \\
\hline
\end{tabular}

et al. [12] studied the influence of strain rate on the small strain shearing rigidity of clay. Zhu et al. [13] thoroughly discussed the loading rate effect of soft clay from many aspects, such as the unity of one-dimensional and threedimensional, the unity of compression and elongation, and the unity of different overconsolidation ratio conditions. Chen et al. [14] studied the acoustic emission characteristics of rock under different loading rates. Di Herve et al. [15] and Tatsuoka et al. [16] performed a series of compression tests with various loading rates in an attempt to establish a constitutive model of sand, taking rheological characteristics into consideration. Consequently, the authors of both papers concluded that the stress-strain relationship of sand is not affected in the range of strain rate they used. Schimming et al. [17] conducted experiments to study shearing resistance of various soil types under both rapid static and dynamic testing conditions using a direct shear device.

Currently, the research on the mechanical properties of lime-treated soil under different loading rates is rarely reported and the curing period is also related to the mechanical properties of lime-treated soil [18]. In view of this, the mechanical properties and long-term strength of lime-treated soil under different loading rates and different curing periods are studied in this paper, which provides services for the design of improving lower subgrade filler.

\section{Experimental Section}

2.1. Test Process. The soils used in the experimental study were collected from a construction site of Jintan construction section, which belongs to the Highway Project from Zhenjiang to Liyang, Jiangsu, China. Tables 1 and 2, respectively, show the index properties and chemical composition of the soil. The grain size distribution curve for test specimens is shown in Figure 1. According to the standard [19], the soil sample is a kind of high liquid limit clay (SC). The lime used in this experiment is a kind of calcium quicklime, which contains $8.5 \% \mathrm{CaO}, 7.03 \% \mathrm{CaCO}_{3}, 79.03 \% \mathrm{Ca}(\mathrm{OH})_{2}$, and $11.4 \%$ loss on ignition.

Lime content was varied as $0 \%, 3 \%, 6 \%, 9 \%$, and $12 \%$ by dry weight of the clay. The maximum dry density and optimum moisture content of treated soil are shown in Figure 2. The moisture of the soil was first determined in order to calculate the quantity of water that should be added to each soil-lime mixture, in order to have the optimum
TABLE 2: Chemical composition of the soil.

\begin{tabular}{lc}
\hline Chemical composition & Quantity \\
\hline $\mathrm{SiO}_{2}$ & 63.17 \\
$\mathrm{Al}_{2} \mathrm{O}_{3}$ & 19.36 \\
$\mathrm{Fe}_{2} \mathrm{O}_{3}$ & 4.32 \\
$\mathrm{TiO}_{2}$ & 0 \\
$\mathrm{~K}_{2} \mathrm{O}$ & 1.73 \\
$\mathrm{Na}$ & $\mathrm{O}$ \\
$\mathrm{MgO}$ & 8.73 \\
$\mathrm{CaO}$ & 1.79 \\
Loss of ignition & 0.67 \\
\hline
\end{tabular}

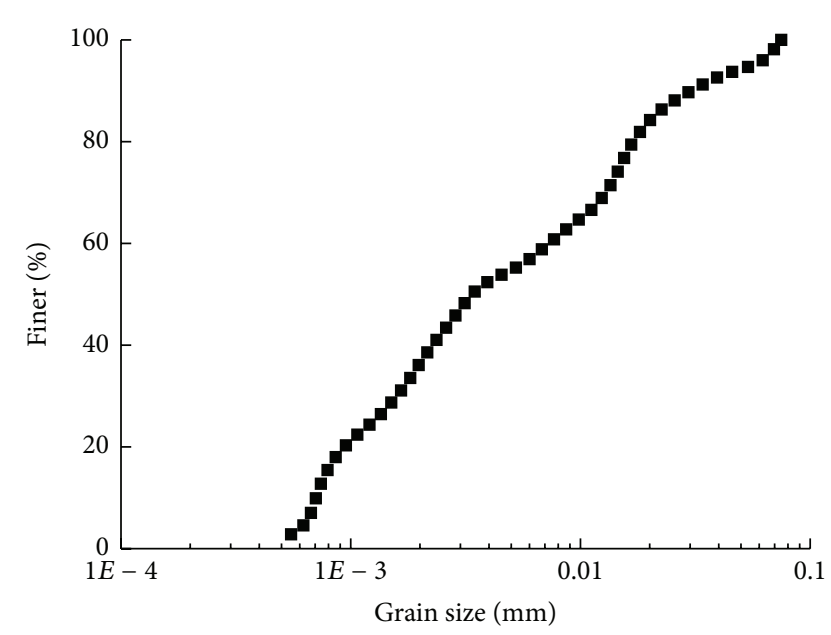

FIGURE 1: Grain size distributions of tested soil.

moisture content for each of the tested samples with different lime contents. Following the mixing process, the soillime mixture was compacted, according to the compaction degree of $98 \%$. The samples are $39.1 \mathrm{~mm}$ in diameter and $80 \mathrm{~mm}$ in height. Immediately after compaction, the lime-soil specimens were removed from the molds and were placed on rigid board in order to prevent handling damage. They were then marked, placed in plastic bags, and sealed. The plastic bags provided an effective means of maintaining the optimum moisture content in the compacted specimens during the curing period. The specimens were then placed in desiccators at room temperature. For the samples prepared, two periods of curing were used alternatively, that is, 7 and 21 days.

The experiment is carried out on the GDS unsaturated triaxial apparatus. It is a kind of strain-controlled instrument, the confining pressure of which is, respectively, 100, 200, and $300 \mathrm{kPa}$ and the strain loading rates are, respectively, $0.1 \% / \mathrm{min}, 1.0 \% / \mathrm{min}, 2.0 \% / \mathrm{min}, 4.0 \% / \mathrm{min}$, and $8.0 \% / \mathrm{min}$.

2.2. Test Results and Analysis. Taking the lime-treated soil sample under the confining pressure of $100 \mathrm{kPa}$ as an example, the curves of stress and strain for lime-treated are shown in Figure 3. It can be seen from the figure that, after the incorporation of the lime, the strength of soil has been significantly improved. When the lime content is 0 , the curve 


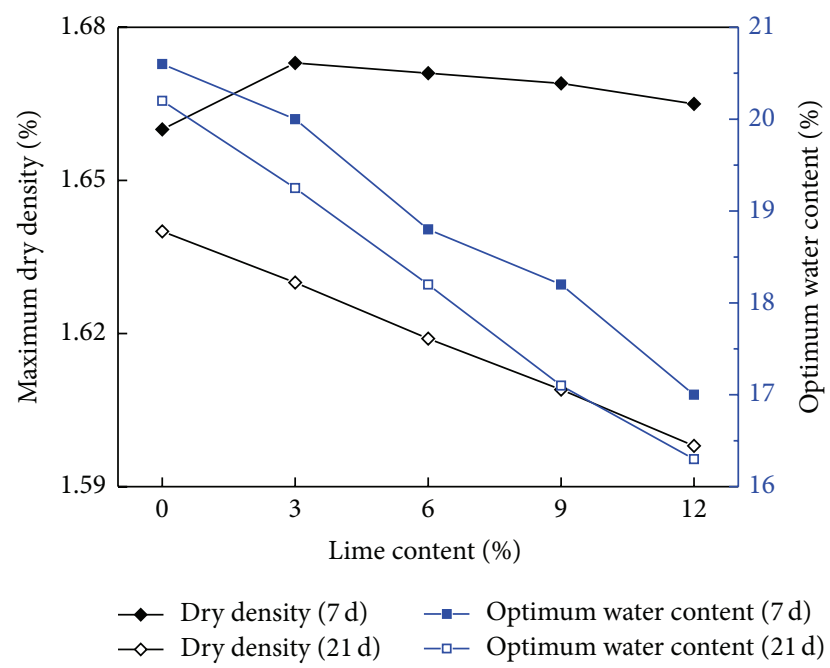

FIGURE 2: Variation of lime contents with maximum dry density and optimum moisture content under different curing periods.

shows strain hardening, while, after the incorporation of the lime, it presents strain softening. The shear strength and the slope of curve (namely, elastic modulus) increase with the increasing of the loading rate, which shows that the larger the loading rate, the steeper the curve.

Taking the confining pressure of $100 \mathrm{kPa}$ as an example, the shear strength and elastic modulus of lime-treated soil with different lime contents and at different loading rates are shown in Figures 4 and 5. As can be seen from the figures, with the increasing of the loading rate, the shear strength shows linear increase in semilogarithmic coordinates. When the curing period is 21 days and the loading rate is increased from $0.1 \% / \mathrm{min}$ to $8 \% / \mathrm{min}$, the shear strength of soil with lime content from 0 to $12 \%$ is, respectively, increased by $62.6 \%$, $44.4 \%, 37.4 \%, 59.2 \%$, and $57.7 \%$. The linear increase of the shear strength in semilogarithmic coordinates is consistent with the opinions of Watanabe [20].

The elastic modulus also increases with the increase of loading rate. When the curing period is 21 days and the loading rate is increased from $0.1 \% / \mathrm{min}$ to $8 \% / \mathrm{min}$, the elastic modulus of soil with lime content from 0 to $12 \%$ is increased by $126 \%, 50.5 \%, 44.3 \%, 24.6 \%$, and $48.1 \%$, respectively.

Under the same loading rate, the shear strength and the elastic modulus firstly increase and then decrease with the increase of the lime content. When the lime content is increased from 0 to $6 \%$, the shear strength and the elastic modulus increase with the increase of the lime content. When the lime content is increased from $6 \%$ to $12 \%$, the shear strength and the elastic modulus gradually decrease.

The mechanical behavior after the curing period of 7 days is basically consistent with that after the curing period of 7 days. The shear strength and the elastic modulus after the curing period of 7 days are less than those after the curing period of 21 days. When the curing period is 7 days, the curing strength and rigidity can reach $70 \% \sim 90 \%$ of those of 21 days.

The shear strength of material includes the cohesion $c$ and the internal friction angle $\phi[21]$. The cohesion and the

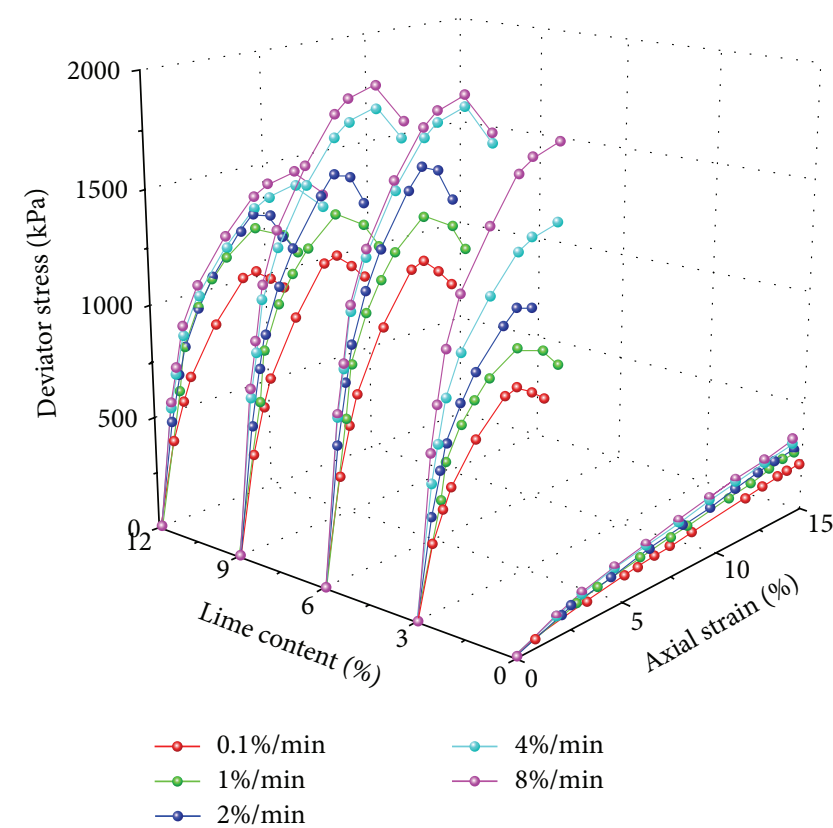

(a)

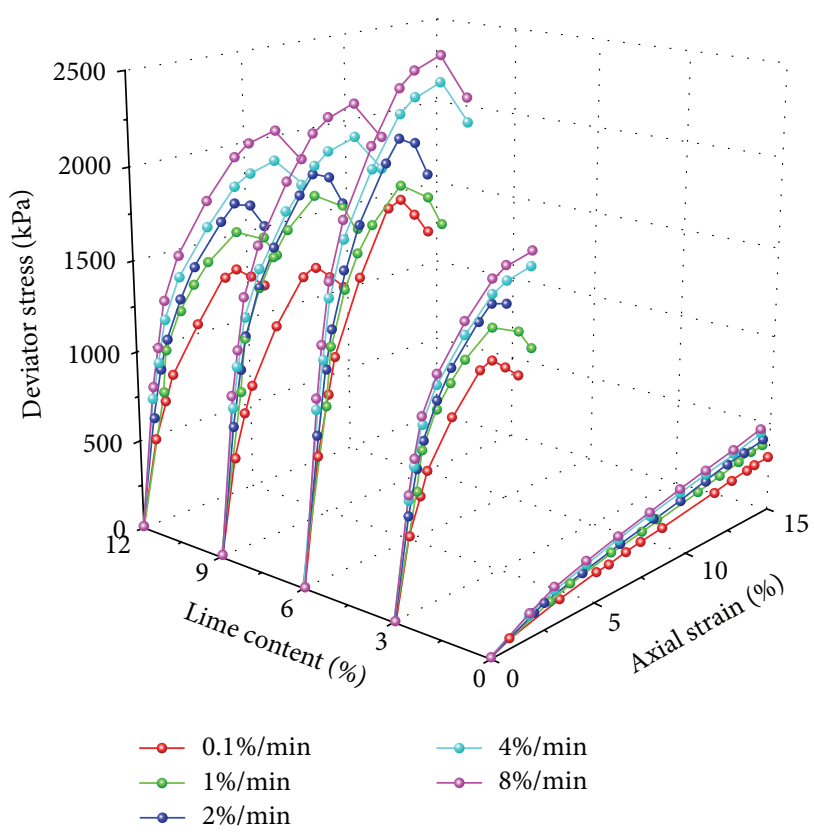

(b)

FigURE 3: Stress-strain curves with different loading rates and lime contents of (a) 7 days and (b) 21 days.

internal friction angle are important physical and mechanical parameters, which can be calculated according to the Mohr stress circle under a different confining pressure that is obtained from triaxial test. The curve about the relationship of loading rate and lime content and that of cohesion and internal friction angle are, respectively, shown in Figures 6 and 7. Due to space limitations, only the change curve of the cohesion and the internal friction angle under the curing period of 21 days are given in this paper. 


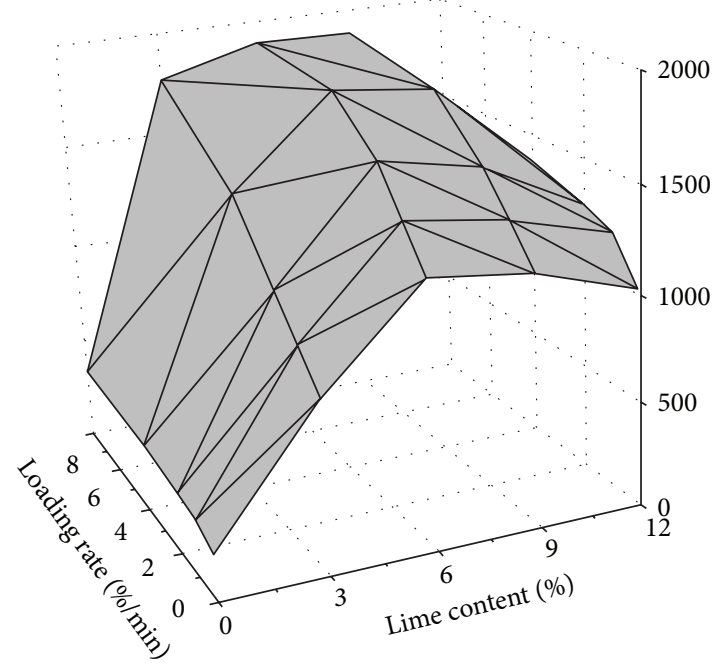

(a)

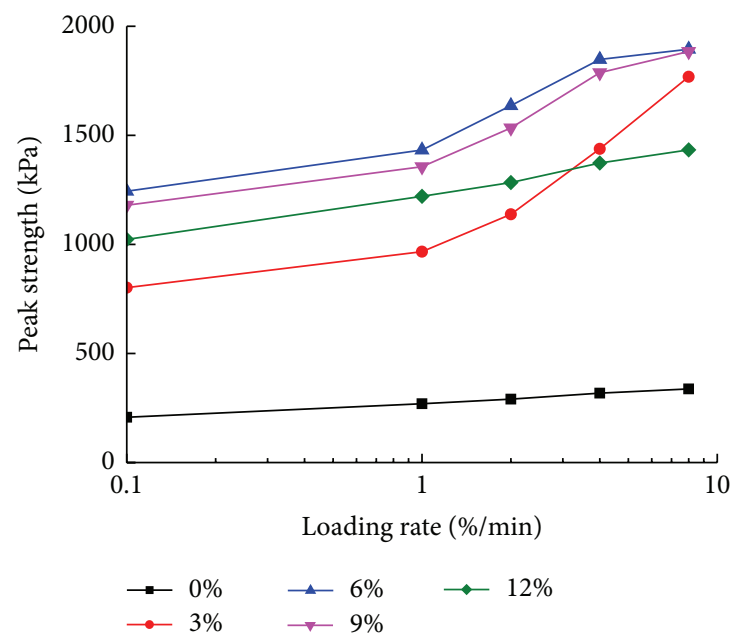

(c)

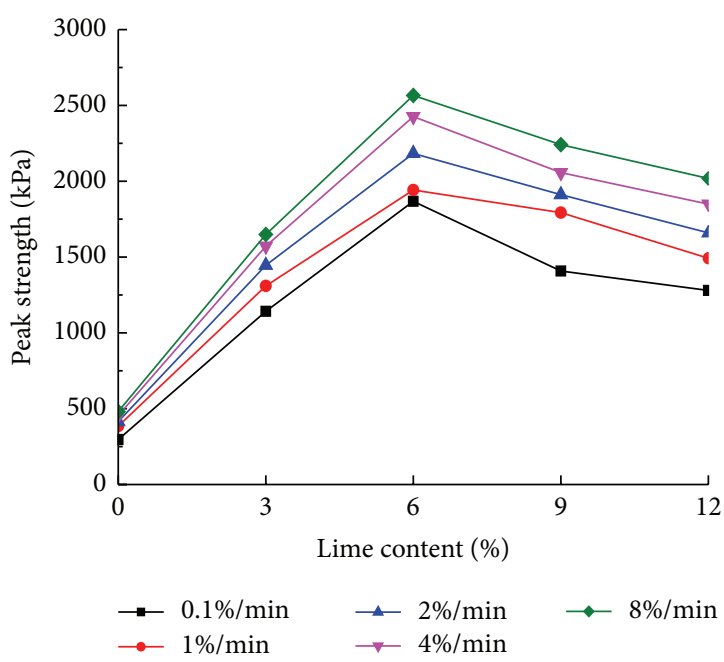

(e)

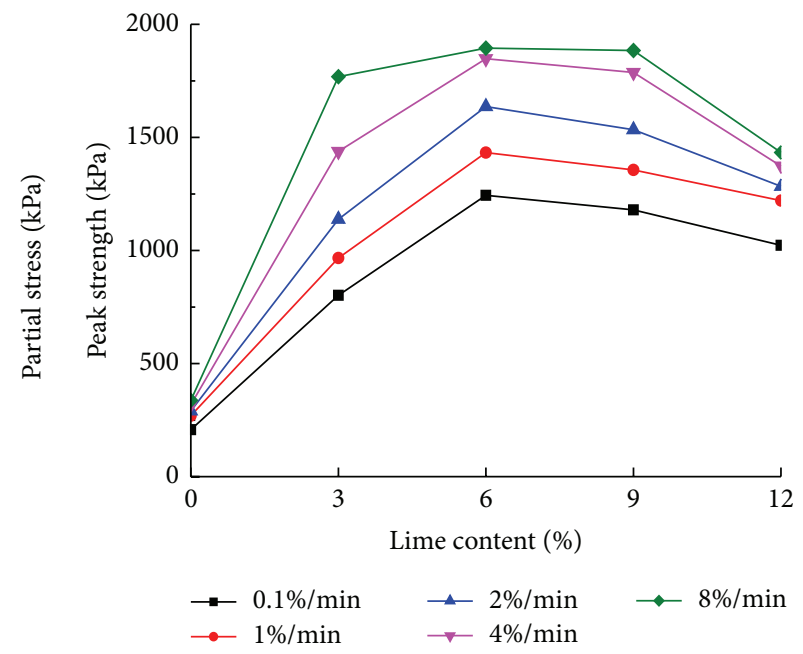

(b)

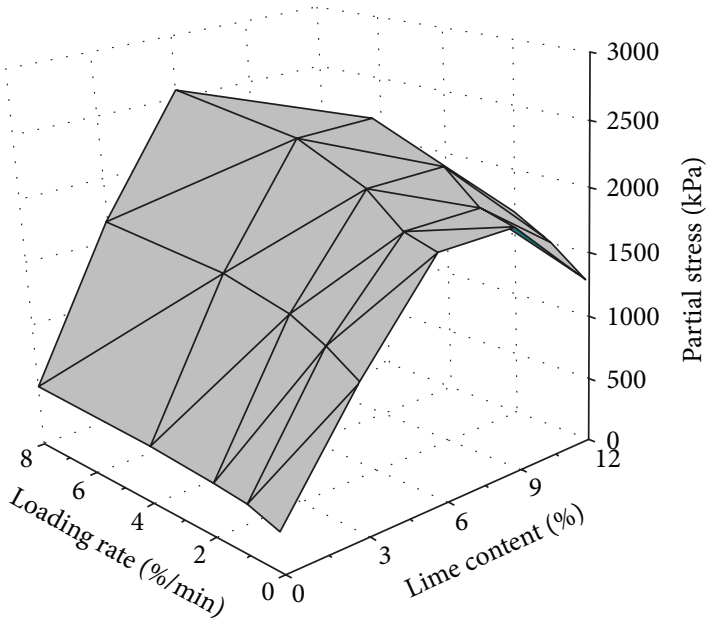

(d)

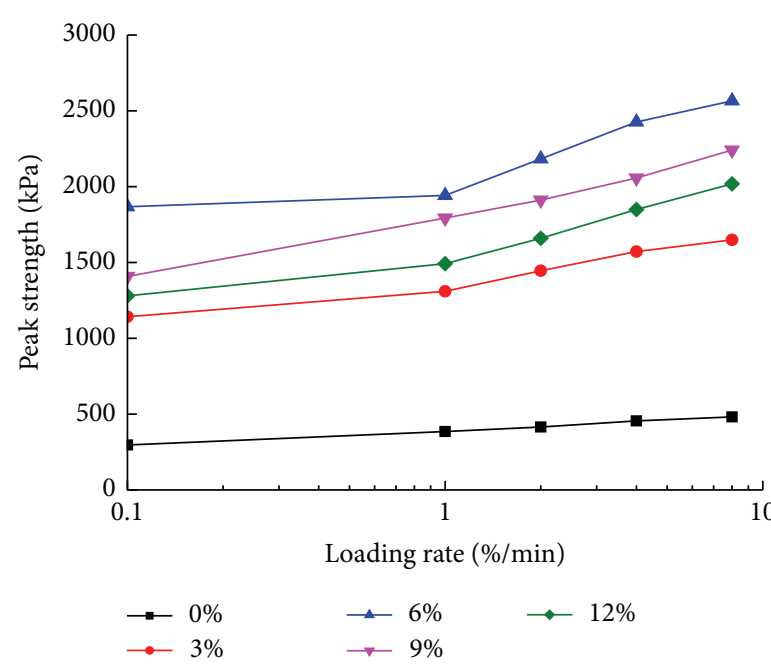

(f)

FIGURE 4: Relation between shear strength and lime content and loading rate of (a) shear strength three-dimensional curved surface (7 days), (b) shear strength lime content (7 days), (c) shear strength loading rate (7 days), (d) shear strength three-dimensional curved surface (21 days), (e) shear strength lime content (21 days), and (f) shear strength loading rate (21 days). 


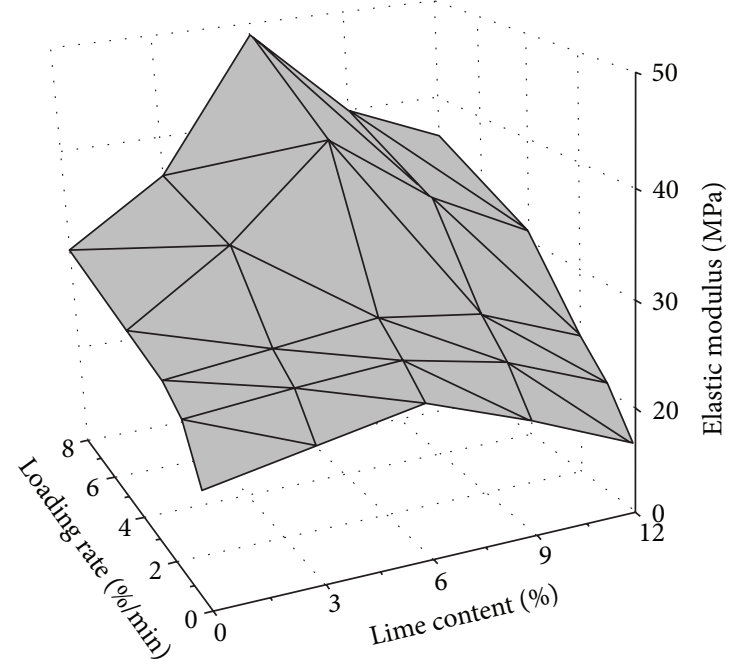

(a)

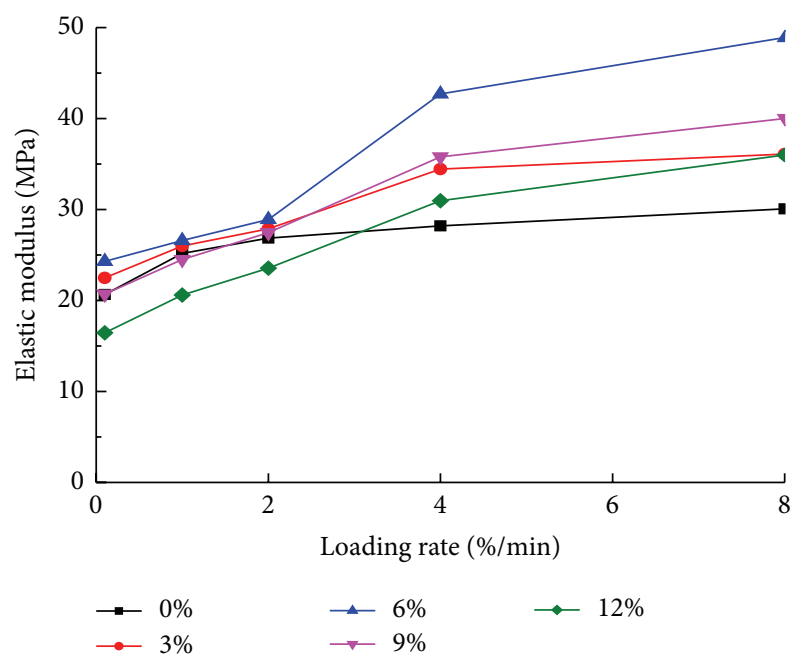

(c)

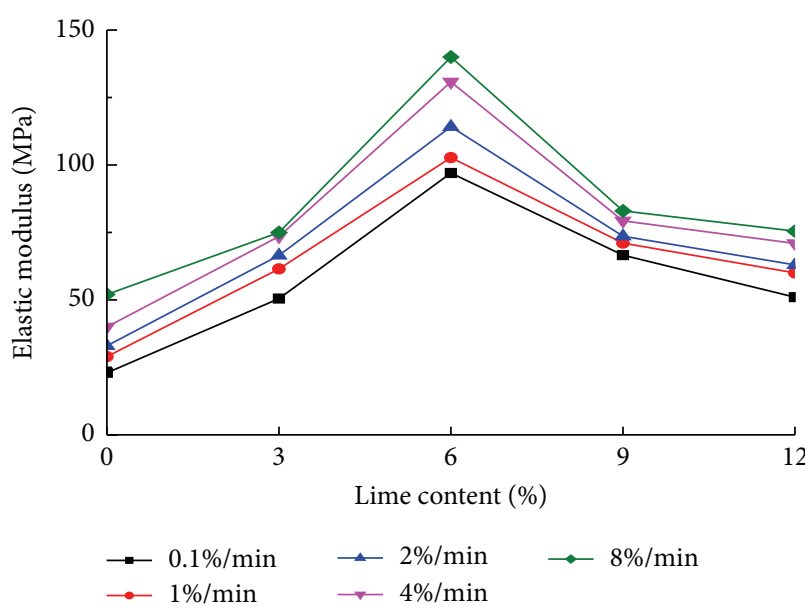

(e)

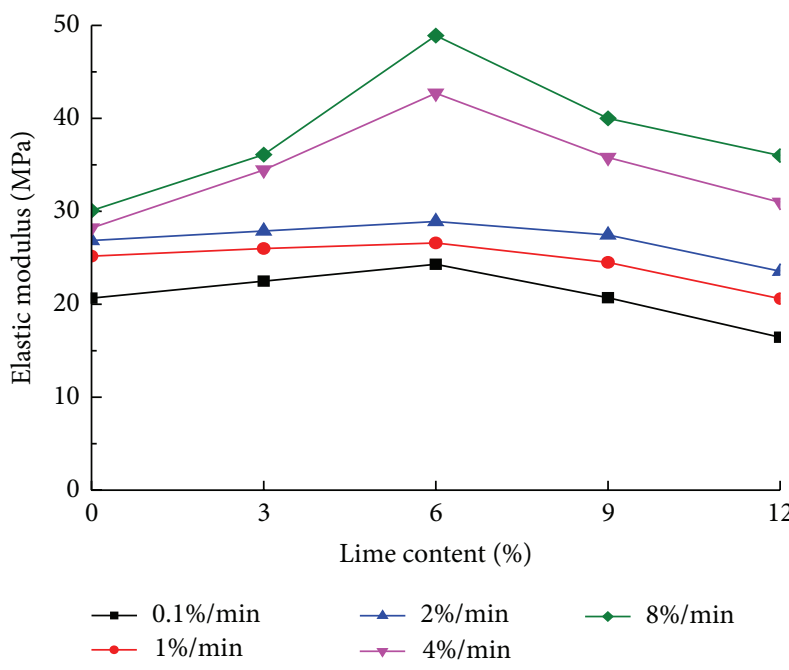

(b)

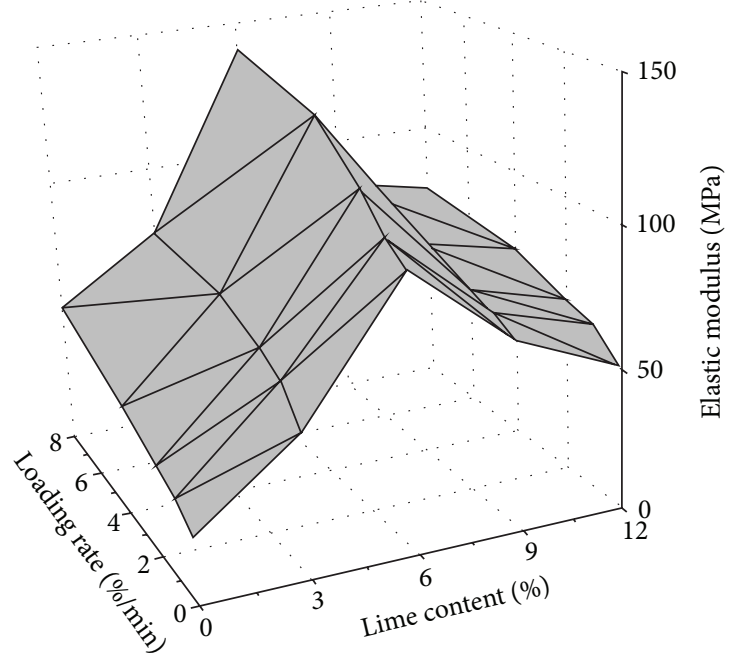

(d)

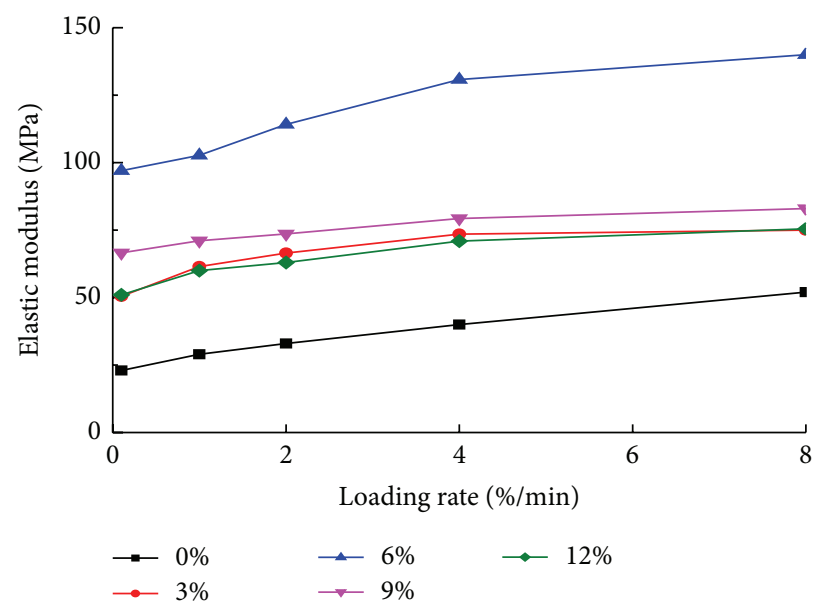

(f)

FIGURE 5: Relation between elasticity modulus and lime content and loading rate of (a) modulus of elasticity three-dimensional curved surface (7 days), (b) modulus of elasticity lime content (7 days), (c) modulus of elasticity loading rate (7 days), (d) modulus of elasticity three-dimensional curved surface (21 days), (e) modulus of elasticity lime content (21 days), and (f) modulus of elasticity loading rate (21 days). 


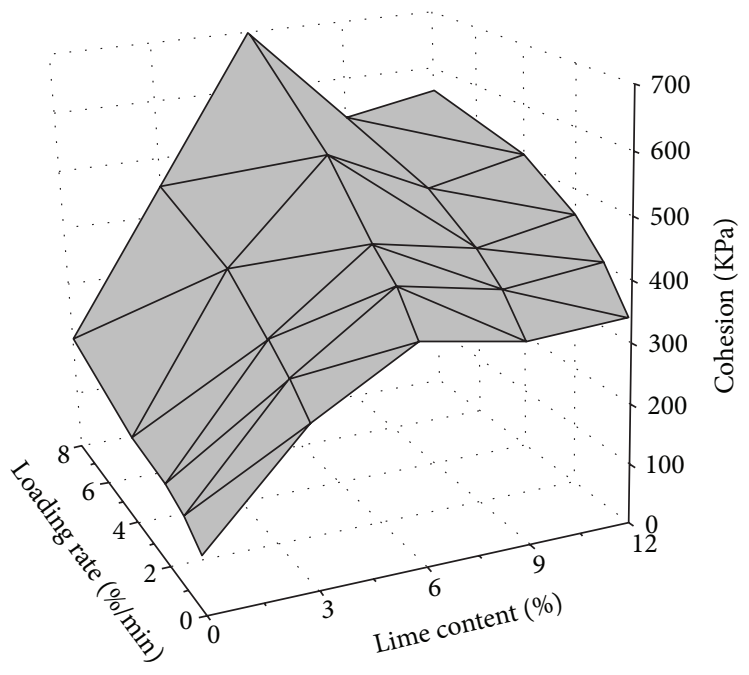

(a)

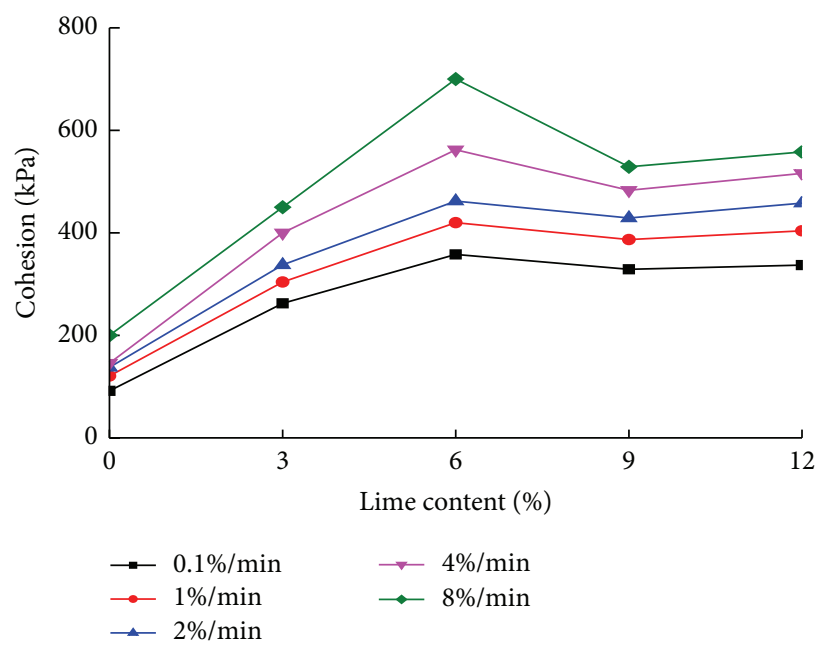

(b)

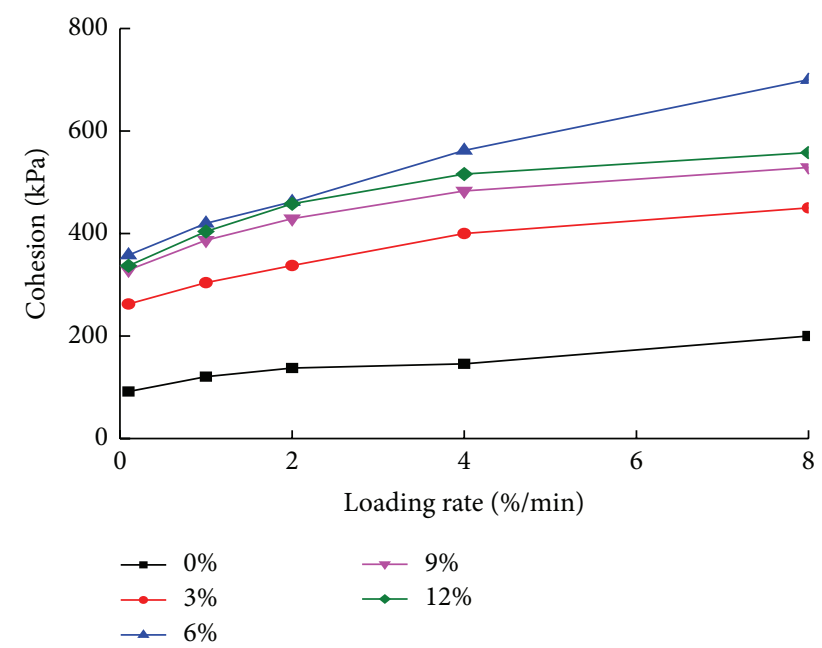

(c)

FiguRE 6: Relation between cohesion and lime content and loading rate of (a) cohesion three-dimensional curved surface (21 days), (b) cohesion lime content (21 days), and (c) cohesion-loading rate (21 days).

The cohesion increases almost linearly with the increase of loading rate. The influence of lime content on the cohesion is basically the same as that on the shear strength and elastic modulus, which means that they all reach the maximum when the lime content is $6 \%$. The loading rate almost has no influence on the internal friction angle, so the curves of friction angle against loading rate exhibit straight horizontal lines. Accordingly, curves of friction angle against lime content overlap with each other and appear as one line. The internal friction angle also reaches the maximum when the lime content is $6 \%$ and then decreases gradually.

The influence of curing periods of 7 days on shear parameters is basically the same as that of 21 days. The cohesion with a curing period of 7 days is smaller than that of 22 days, the strength of which equals $70 \%$ to $90 \%$ of that with a curing period of 22 days. The curing period has less influence on the internal friction angle, which means only a slight decrease whose biggest drop is $7 \%$ can be observed.

\section{Discussion}

3.1. Improvement Mechanism of Lime to Soil. There are many aspects for the improvement effect of lime to soil:

(1) Because lime has a flocculation effect on expansive clay particles, which can change the organizational structure of soil particles, the $\mathrm{Ca}^{2+}$ and $\mathrm{Mg}^{2+}$ ions in expansive soil increase greatly with the incorporation of lime. However due to the digestion action and the exchange interaction of cations when we mix lime with water, the $\mathrm{Na}^{+}$and $\mathrm{K}^{+}$ions in expansive soils are gradually replaced by $\mathrm{Ca}^{2+}$ and $\mathrm{Mg}^{2+}$, which significantly reduces the plasticity index of expansive soil [22].

(2) When the mixture has a low content of lime, it contains mainly prime soil and the lime particles just fill in pores formed by the skeleton of prime soil particles. 


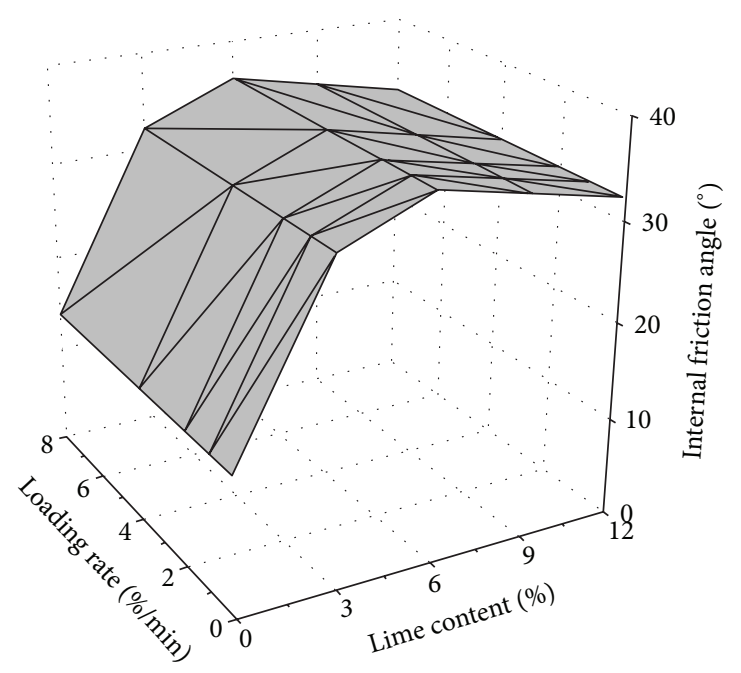

(a)

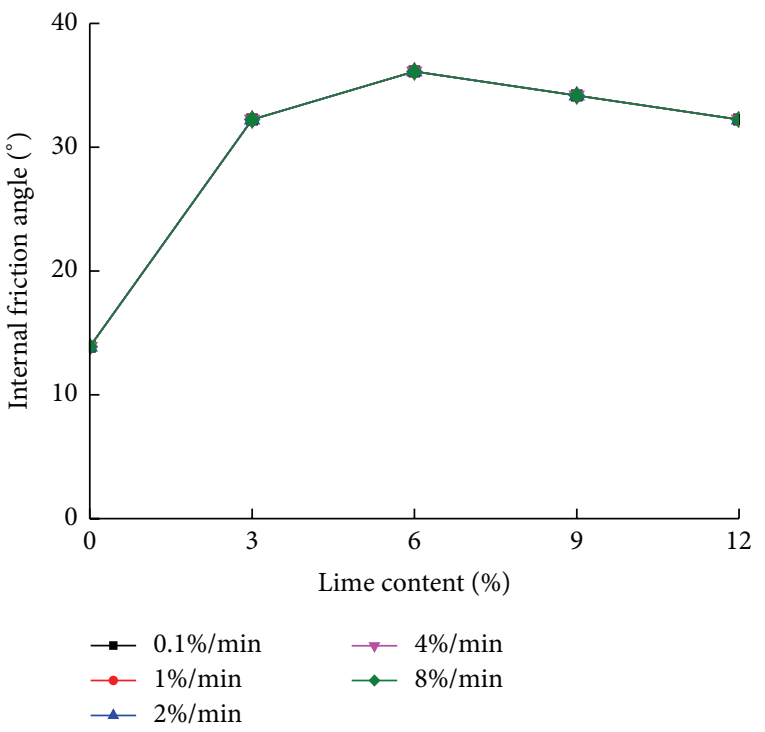

(b)

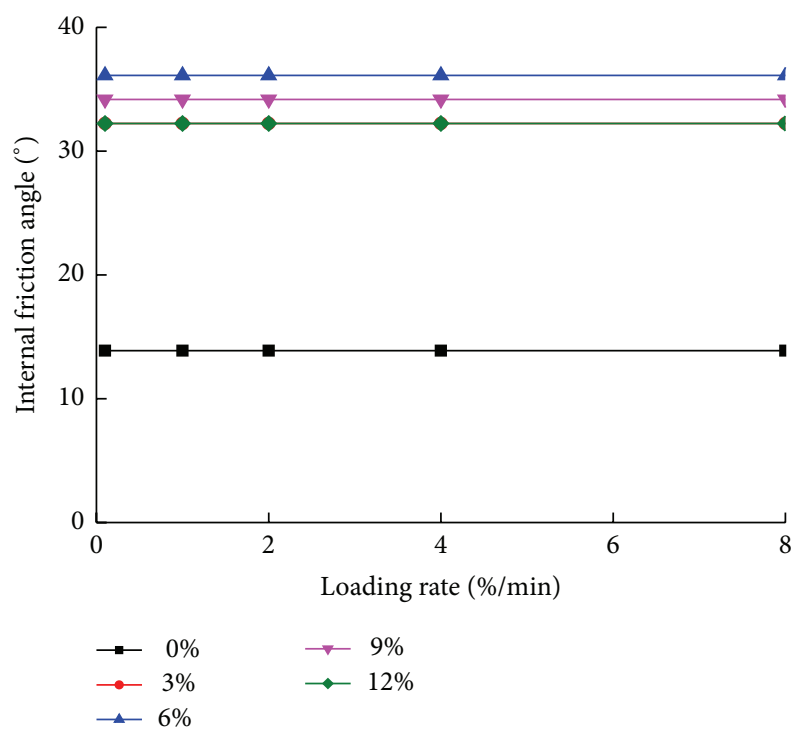

(c)

FIGURE 7: Relation between internal friction angle and lime content and loading rate of (a) internal friction angle three-dimensional curved surface (21 days), (b) internal friction angle lime content (21 days), and (c) internal friction angle loading rate (21 days).

When the porosity decreases, the density increases and lime and soil play a role as skeleton, which forms a force chain structure and enhances the strength. With the constant increase of lime content, the soil particles are separated, the link between which disappears. As a result, the structure is damaged and the strength decreases.

(3) When the lime enters the pores of soil particles, due to the small friction on lime surface, which plays a role of lubricating, the cohesion and internal friction angle will be reduced.

(4) The strength development in the soil-lime mixture specimen is controlled by liquid alkaline activator. In the present work, the liquid alkaline activator is the lime. The lime leaches the silicon and aluminum in amorphous phase of lime and the calcium silicate solution $\left(\mathrm{CaSiO}_{3}\right)$ acts as a binder. The soil contains alumino-silicates layers with both external and internal negative layer surfaces that act as a huge anion and a swarm of positively charged cations (such as $\mathrm{Na}^{+}, \mathrm{K}^{+}, \mathrm{Ca}^{+}$, and $\mathrm{Mg}^{+}$) [23]. Therefore, some of the input lime content to leach the silicon and aluminum in amorphous phase of lime were absorbed by the negative charges between clay layers (diffusion double layers) and form an ionic interlayer. Consequently, the lime-treated soil specimens need $\mathrm{NaOH}$ for geopolymerization, hence the strength increases rapidly with lime content until 6\% lime content. The reduction in strength at relatively high lime content is because the amount of $\mathrm{OH}^{-}$from the liquid alkaline activator exceeds the requirement for geopolymerization process. 
In this paper, the best lime content is $6 \%$, which may be different for different kinds of soils.

\subsection{The Influence of Loading Rate on Mechanical Behavior.} General trends observed in compression tests varying a wide range of strain rate are that lime-treated soil exhibits stiffer response and higher shear strength when the soil sample is subjected to faster strain rates, and the rate of strength increases approximately linearly with an increase in the loading rate in the semilogarithmic plot. This conclusion is well in agreement with the findings from soil and clay proposed by Watanabe and Kusakabe [20] and Ito and Fujimoto [23].

The influences of loading rate on geotechnical materials can be summarized as the following three aspects:

(1) When the loading rate is small, there will be sufficient reaction time for the production of pore water pressure, which decreases the effective stress, making the strength reduce.

(2) Lee et al. [24] suggested that the change in mechanism of strength mobilization is mainly due to the effect of strain rate on the energy required for particle crushing. Although the evidence of particle crushing was not provided in their paper, particle crushing might have occurred in their tests, considering the data of crushing strength of sand.

(3) Pincus et al. [25] suggested that the reason for this phenomenon is related with volume change caused by the particle crushing and rear-ranging during shear. As the fracturing and rearranging of soil grains requires time, the increment in strain rate leads to less time of the fracturing and rearranging for soil grains, thereby decreasing amounts of the particle crushing and rearranging.

Based on unsaturated soil mechanics theory proposed by Fredlund and Rahardjo [26], a three-dimensional manner composed of two stress state variables can be drawn: the net normal stress and the lime content. In other words, the three-dimensional manner is Mohr-Coulomb circles with respect to the lime content for unsaturated lime-treated soils. In Figure 8, the failure envelopes for unsaturated specimens of clean clay are obtained by drawing the Mohr-Coulomb circles on a two-dimensional plot, as the lime content is 0 . In the case of lime-treated soils, the Mohr-Coulomb circles are plotted in the same way as Mohr-Coulomb circles. However, the location of Mohr-Coulomb circle of lime-treated soils is a function of the lime content in the three-dimensional manner. The failure envelopes onto the shear stress $(\tau)$ versus the net normal stress plane were determined by Mohr-Coulomb circles. The intersection between the failure envelope and the ordinate is a total cohesion $(c)$, and tilt angle is internal friction angle $\phi$. It must be pointed out that failure states under a higher strain rate are illustrated with the dashed lines as well as those under a lower strain rate drawn by the solid lines. The internal friction angle $\phi$ is assumed to be constant regardless of stress state variables. Note that the slopes of failure envelopes for lime-treated specimens

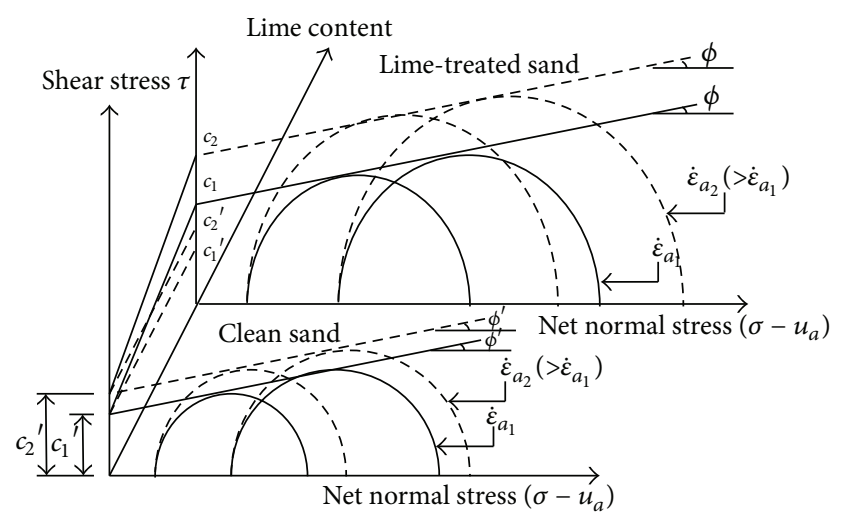

FIGURE 8: Diagrammatic sketches of three-dimensional failure surface for unsaturated soils.

commenced at the same angle, because the internal friction angle tends to be constant irrespective of loading rate, while the cohesion increases with the increase of loading rate.

This result on the effect of loading rate on internal friction angle does not agree with that of Fukuoka et al. [27] and Saomoto et al. [28], at which Fukuoka et al. [27] examined the influence of internal friction angle of granular materials including Toyoura sand and glass beads by a high speed ring shear apparatus and observed the increase in internal friction angle of Toyoura sand and no change in friction angle of the glass beads with increasing the rate of shearing. Fukuoka et al. [27] suggested that the increase in internal friction angle of Toyoura sand is due to particle crushing, while threedimensional DEM simulation of ring shear test reported by Saomoto et al. [28] shows that the increase in strain rate results in a slight increase in friction angle.

\section{Conclusion}

(1) The shear strength, elastic modulus, and cohesion all increase with the increase of loading rate, among which the shear strength shows linear increase in semilogarithmic coordinates. The loading rate has no influence on the internal friction angle.

(2) Under the same loading rate, the shear strength, elastic modulus, cohesion, and internal friction angle firstly increase and then decrease with the increase of lime content. When the lime content increases from 0 to $6 \%$, the parameter values increase with the increase of lime content. When the lime content increases from $6 \%$ to $12 \%$, the parameter values decrease gradually.

(3) The mechanical behavior after the curing period of 7 days is basically similar with that after the curing period of 7 days. The shear strength and the elastic modulus after the curing period of 7 days are less than that after the curing period of 21 days.

\section{Conflict of Interests}

The authors declare that there is no conflict of interests regarding the publication of this paper. 


\section{Acknowledgments}

This work was supported by Scientific and Technological Research Program of Chongqing Municipal Education Commission (Grant nos. KJ1501007, KJ1501020 and KJ1501031), Scientific and Technological Research Program of Wanzhou District Science and Technology Commission (Grant no. 201404011), Scientific Research Innovation Team Program of the Three Gorges Reservoir Bank Water Rock Interaction and Mechanism of Landslide, and Young Scientific Program of Chongqing Three Gorges University (Grant no. 14QN28). Thanks are due to their support and assistance.

\section{References}

[1] N. Little D, Evaluation of Structural Properties of Lime Stabilized Soils and Aggregates, National Lime Association, 1987.

[2] J.-M. Bian, L. Jiang, and B.-T. Wang, "Subgrade construction control parameters for lime-treated expansive soils," Journal of Chang'an University, vol. 34, no. 2, pp. 51-58, 2014 (Chinese).

[3] B. R. Phanikumar, "Effect of lime and fly ash on swell, consolidation and shear strength characteristics of expansive clays: a comparative study," Geomechanics and Geoengineering, vol. 4, no. 2, pp. 175-181, 2009.

[4] B. R. Phanikumar, R. Sreedharan, and C. Aniruddh, "Swellcompressibility characteristics of lime-blended and cementblended expansive clays-a comparative study," Geomechanics and Geoengineering, vol. 10, no. 2, pp. 153-162, 2015.

[5] O. Amu, O. Bamisaye, and I. Komolafe, "The suitability and lime stabilization requirement of some lateritic soil samples as pavemen," International Journal of Pure and Applied Sciences and Technology, vol. 2, no. 1, pp. 29-46, 2011.

[6] N. Yarbaşi, E. Kalkan, and S. Akbulut, "Modification of the geotechnical properties, as influenced by freeze-thaw, of granular soils with waste additives," Cold Regions Science and Technology, vol. 48, no. 1, pp. 44-54, 2007.

[7] J.-R. Zhang and X. Cao, "Stabilization of expansive soil by lime and fly ash," Journal of Wuhan University of TechnologyMaterials Science Edition, vol. 17, no. 4, pp. 73-77, 2002.

[8] H. Bekki, Z. Djilaili, Y. Tlidji, and T. H. Daouadji, "Durability of treated silty soil using lime and cement in road construction-a comparative study," The Online Journal of Science and Technology, vol. 5, no. 2, pp. 23-31, 2015.

[9] Y. Zhang, T. Ishikawa, T. Tokoro, and T. Nishimura, "Influences of degree of saturation and strain rate on strength characteristics of unsaturated granular subbase course material," Transportation Geotechnics, vol. 1, no. 2, pp. 74-89, 2014.

[10] J. A. Díaz-Rodríguez, J. J. Martinez-Vasquez, and J. C. Santamarina, "Strain-rate effects in Mexico City soil," Journal of Geotechnical and Geoenvironmental Engineering, vol. 135, no. 2, pp. 300-305, 2009.

[11] H. Martindale, T. Chakraborty, and D. Basu, "A strain-rate dependent clay constitutive model with parametric sensitivity and uncertainty quantification," Geotechnical and Geological Engineering, vol. 31, no. 1, pp. 229-248, 2013.

[12] K. K. Sorensen, B. A. Baudet, and B. Simpson, "Influence of strain rate and acceleration on the behaviour of reconstituted clays at small strains," Geotechnique, vol. 60, no. 10, pp. 751-763, 2010.
[13] Q.-Y. Zhu, Z.-Y. Yin, J.-G. Zhu, J.-H. Wang, and X.-H. Xia, "Progress and trend of experimental investigation on ratedependent behavior of soft clays," Rock and Soil Mechanics, vol. 35, no. 1, pp. 7-24, 2014 (Chinese).

[14] Y.-L. Chen, Z.-A. Wei, J. Xu, X.-J. Tang, H.-W. Yang, and S.-C. Li, "Experimental research on the acoustic emission characteristics of rock under uniaxial compression," Journal of China Coal Society, vol. 36, supplement 2, pp. 237-240, 2011 (Chinese).

[15] B. Di Herve, F. Tatsuoka, and M. Ishihara, “Time-dependent shear deformation characteristics of sand and their constitutive modelling," Soils and Foundations, vol. 42, no. 2, pp. 1-22, 2002.

[16] F. Tatsuoka, H. Dibenedetto, T. Enomoto, S. Kawabe, and W. Kongkitkul, "Various viscosity types of geomaterials in shear and their mathematical expression," Soils and Foundations, vol. 48, no. 1, pp. 41-60, 2008.

[17] B. B. Schimming, H. J. Haas, and H. C. Saxe, "Study of dynamic and static failure envelopes," Journal of the Soil Mechanics and Foundations Division, vol. 92, no. 2, pp. 105-124, 1966.

[18] M. S. Ouf, "Effect of using pozzolanic materials on the properties of Egyptian soils," Life Science Journal, vol. 9, no. 1, pp. 554-560, 2012.

[19] Ministry of Water Resources of the People's Republic of China, "Standard for engineering classification of soil," Tech. Rep. GB/T50145-2007, China Planning Press, 2008 (Chinese).

[20] K. Watanabe and O. Kusakabe, "Reappraisal of loading rate effects on sand behavior in view of seismic design for pile foundation," Soils and Foundations, vol. 53, no. 2, pp. 215-231, 2013.

[21] J.-J. Xu, Z.-A. Wei, Y.-L. Chen, and Y. Yang, "Experimental study of relationship between electric resistivity and mechanical properties of phosphate tailings," Chinese Journal of Rock Mechanics and Engineering, vol. 33, no. 10, pp. 2132-2137, 2014 (Chinese).

[22] Y.-L. Chen, "Microstructure of expansive soil from Yunnan Province," Chinese Journal of Geotechnical Engineering, vol. 35, no. 1, pp. 334-339, 2013.

[23] S. Horpibulsuk, N. Yangsukaseam, A. Chinkulkijniwat, and Y. J. Du, "Compressibility and permeability of Bangkok clay compared with kaolinite and bentonite," Applied Clay Science, vol. 52, no. 1-2, pp. 150-159, 2011.

[24] K. L. Lee, H. B. Seed, and P. Dunlop, "Effect of transient loading on the strength of sand," in Proceedings of the 7th International Conference on Soil Mechanics and Foundation Engineering, pp. 239-247, Mexico City, Mexico, 1969.

[25] H. Pincus, J. Yamamuro, and P. Lade, "Effects of strain rate on instability of granular soils.," Geotechnical Testing Journal, vol. 16, no. 3, article 304, 1993.

[26] D. G. Fredlund and H. Rahardjo, Soil Mechanics for Unsaturated Soils, John Wiley \& Sons, New York, NY, USA, 1993.

[27] H. Fukuoka, K. Sassa, and M. Shima, "Shear characteristics of sandy soils and clayey soils subjected to the high-speed and 
high-stress ring shear tests," Annuals of Disaster Prevention Research Institute of Kyoto University B, vol. 1, no. 33, pp. 179190, 1990.

[28] H. Saomoto, T. Matsushima, and Y. Yamada, "Three-dimensional discrete element simulation of ring shear test," in Proceedings of the 12th Japan Earthquake Engineering Symposium, pp. 578-591, 2006. 

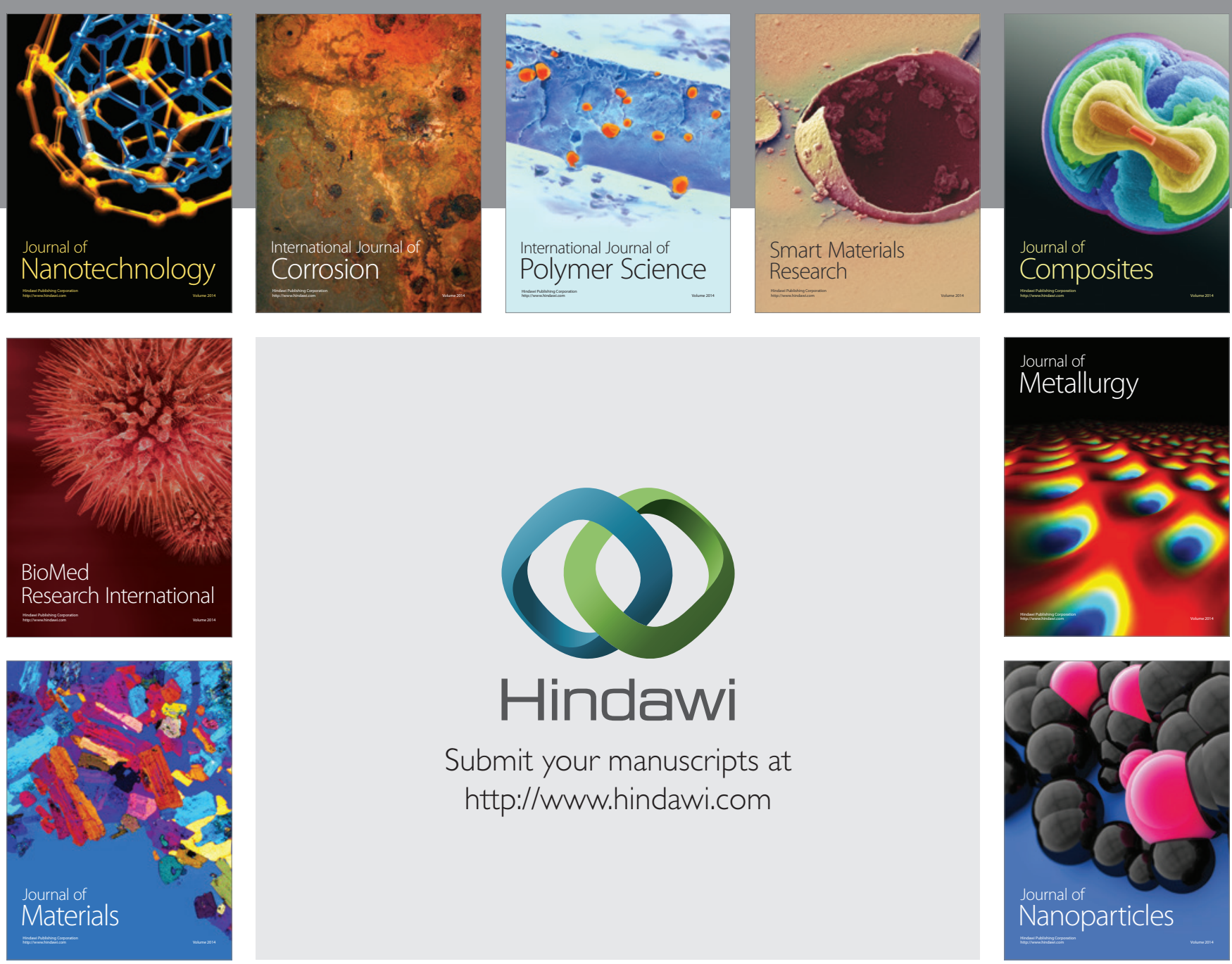

Submit your manuscripts at http://www.hindawi.com
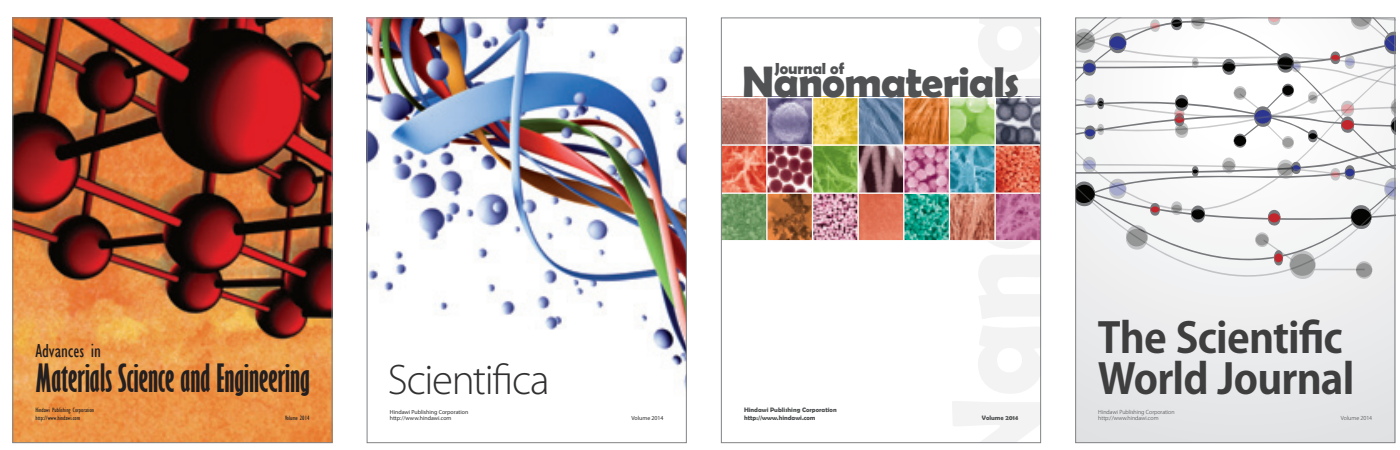

\section{The Scientific World Journal}
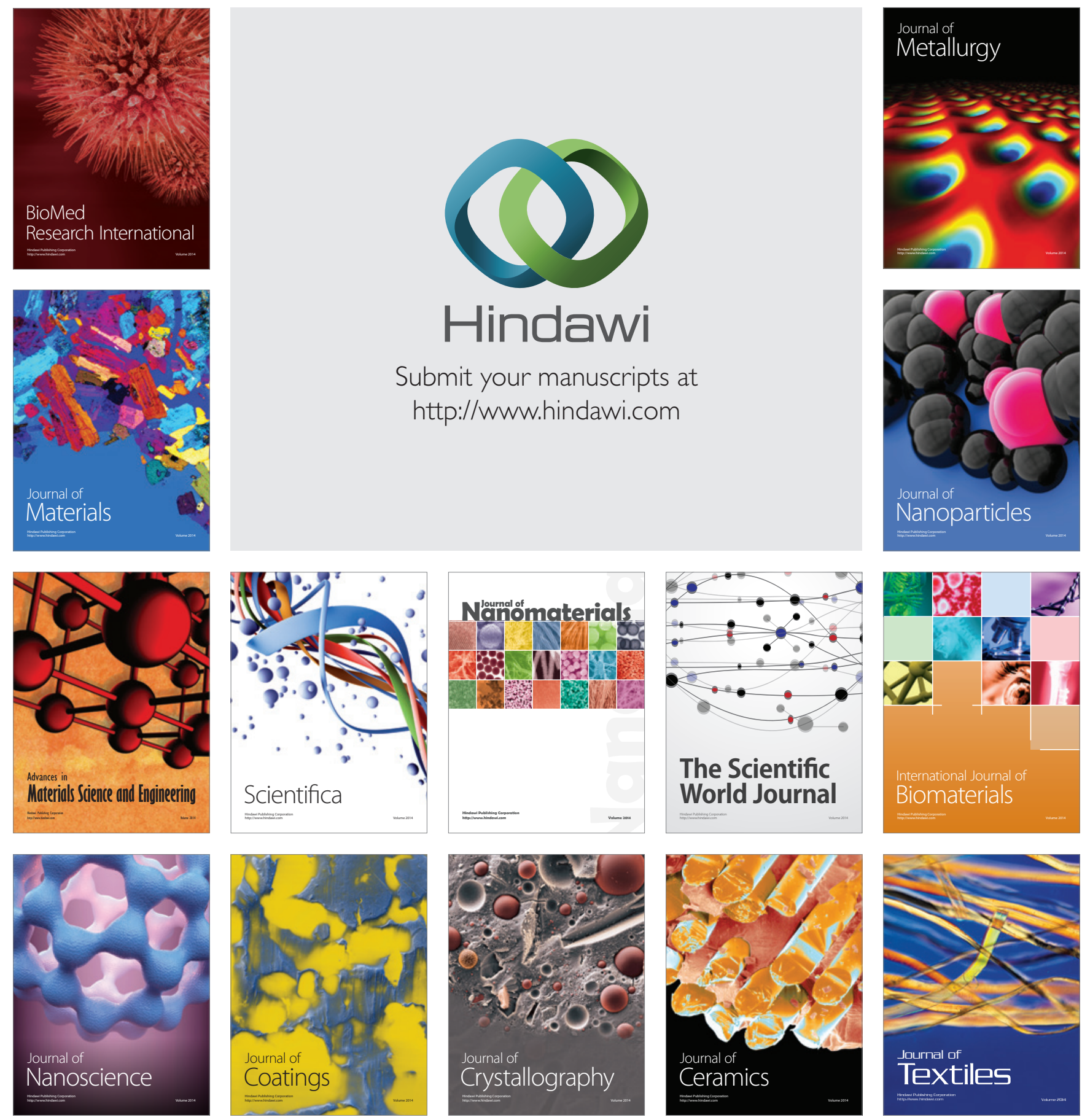